\title{
INEQUALITIES FOR THE $p$-ANGULAR DISTANCE IN NORMED LINEAR SPACES
}

\author{
SEVER S. DRAGOMIR
}

Abstract. New upper and lower bounds for the $p$-angular distance in normed linear spaces are given. Some of the obtained upper bounds are better than the corresponding results due to $\mathrm{L}$. Maligranda recently established in the paper [Simple norm inequalities, Amer. Math. Monthly, 113(2006), 256-260].

Mathematics subject classification (2000): 46B05, 46B99, 26D15.

Keywords and phrases: normed linear spaces, angular distance, norm inequalities.

\section{REFERENCES}

[1] N. BOURBAKI, Integration, Herman, Paris, 1965.

[2] P. S. Bullen, Handbook of Means and Their Inequalities, Kluwer Academic Publishers, Dordrecht/Boston/London, 2003.

[3] V. I. GURARII, Strengthening the Dunkl-Williams inequality on the norm of elements of Banach spaces, Dopovidi Akad. Nauk Ukrain RSR 1966(1966), 35-38 (Ukrainian).

[4] G. N. HILE, Entire solutions of linear elliptic equations with Laplacian principal part, Pacific J. Math 62(1976), 124-140.

5] L. Maligranda, Simple norm inequalities, Amer. Math. Monthly, 113(2006), 256-260.

[6] D. S. Mitrinović, J. E. PeČArić And A. M. FinK, Classical and New Inequalities in Analysis, Kluwer, Dordrecht, 1993. 